\title{
Counselors' Adjective Correlates of Working Alliance
}

\author{
Cass Dykeman ${ }^{1}$, N. Kenneth LaFleur ${ }^{2}$ \\ ${ }^{1}$ Oregon State University \\ ${ }^{2}$ University of Virginia
}

This is the author's preprint. The copy of record was published as the following:

Dykeman, C., \& LaFleur, N. K. (1996). Counselors' adjective correlates of working alliance.

Psychological Reports, 78(2), 563-570. https://doi.org/ 10.2466/pr0.1996.78.2.563

\section{Introduction}

The authors present a study of 85 counselors' adjective descriptors of clients in relation to a working alliance. The imperative for such a study emerges from Gough's 1965 Conceptual Analysis of Test Scores approach to clinical measurement. For this investigation, all 300 items of the Adjective Check List were used. Working affiance was measured by the counselor's form of the Working Alliance InventoryShort. Point biserial correlation of each adjective with inventory scores produced 54 significant adjectives. These 54 adjectives were 18 times the number expected by chance.

Few contemporary developments in psychology rival the effect of working alliance. This construct can predict psychotherapy outcomes to an extent unrecognized previously (for reviews of this literature 
see: Gelso \& Carter, 1994; Horvath, 1994b; Horvath \& Symonds, 1991; Luborsky, 1994; Marziali \& Alexander, 1991; Sexton \& Whiston, 1994). However, while the relationship between working alliance and treatment outcome is well documented, there has been no empirically derived description of this robust predictor variable. Only clinical descriptions of working alliance have appeared in the literature. This study was done to help fill this gap in the literature.

The imperative for the present study emerges from the work of Gough $(1960,1965,1983)$, who outlined a general methodological system of test score interpretation for psychotherapists. He called this system Conceptual Analysis of Test Scores. The cornerstone of this system is the idea that the validity of any measure resides in the range and structural clarity of the information it provides a counselor about the individual client with whom he works (Gough, 1965). Thus, a critical element of this analysis is the systematic study of individuals whose scale scores differ (Megargee, 1972). As Gough (1965) pointed out, two tests may be equal in forecasting a particular criterion, yet differ widely in their personological implications.

The Conceptual Analysis of Test Scores has three levels of evaluation: (a) Primary Evaluation, (b) Secondary Evaluation, and (c) Tertiary Evaluation. Primary Evaluation encompasses traditional validity and reliability issues in test construction. Extensive work concerning these issues and the most used working affiance instrument, Working Alliance 
Inventory, has appeared in the literature (Horvath, 1994a; Horvath \& Greenberg, 1986, 1989; Horvath \& Symonds, 1991). Tertiary Evaluation concerns the unexpected clinical utility of a measure discovered through its research use. Gough (1965) gave as an example of Tertiary Evaluation the discovery that the Socialization scale of the California Personality Inventory is a strong predictor of academic achievement. Tertiary Evaluation is not a focus of this study.

Gough (1965) noted that Secondary

Evaluation aims to discover the psychological basis of measurement and to specify the meaning of that which is measured. Gough concluded that "a scale may forecast some important nontest behavior, such as the likelihood of improvement in psychotherapy, and thus meet the requirements of our primary evaluation; but the clinician needs to know more than this; he must know what it is that the scale reflects that leads to this favorable potentiality" (p. 295). According to Gough, Secondary Evaluation is a four-step process. Gough (1965) defined these steps as follows: (1) Review of the development of the measure, the procedures and samples used in its construction, its theoretical presupposition and bases; (2) Analysis of the components of the measure, its items, stimulus materials, and content; (3) Determination of the relationships between the measure and (a) other measures already known and conceptualized, and (b) variables of self-evident importance such as sex, age, and status; and (4) Specification of the characterological and 
personological dispositions of individuals who obtain scores defined by the measure itself as diagnostically significant. The professional literature on working affiance has addressed all the elements of step 1 (Horvath, 1994a; Horvath \& Greenberg, 1986, 1989), step 2 (Horvath, 1994a; Horvath \& Greenberg, 1986, 1989; Tracey \& Kokotovic, 1989), step 3a (Luborsky, 1994; Safran \& Wallner, 1991; Tichenor \& Hill, 1989), and step 3b (Kivlighan \& Schmitz, 1992; Speight, 1990). Absent from the literature is a consideration of the contents of step 4 - a specification of the personological dispositions of clients who obtain scores defined by a measure itself as clinically significant (Gough, 1965).

To assess step 4 of Gough's Conceptual Analysis of Test Scores, the present adjective correlate study of working affiance measurement was conducted. As noted above, working alliance represents a critical predictor of treatment outcome. Thus, completion of step 4 of Secondary Evaluation will permit full application of a powerful theory to clinical practice.

\section{Method}

\section{Participants}

The participants were drawn from 21 university counseling centers and student mental health units from across the US. The subjects were recruited through directors, training directors, and research coordinators at these sites. Student 
enrollment at the institutions where these counselors served ranged from 4,692 to 42,780. A total of 150 counselors was asked to take part in the study. A total of 93 counselors returned the questionnaire packet of which 85 ( $57 \%$ of total sent out) contained enough data to be included as part of the analyses.

The participants included both staff counselors and interns. The mean age of the participants was 42 yr. $(S D=10)$. Women represented $55 \%$ of the sample. The mean number of years of professional experience was $11(S D=9)$. The majority of the participants possessed doctorates $(67 \%)$. The two most common theoretical orientations among the participants were psychodynamic (35\%) and cognitive (21\%).

\section{Measures}

Working alliance was assessed by means of the short form of the Working Alliance Inventory. The Working Alliance Inventory is a self-report measure designed to gauge the quality of psychotherapeutic alliances. Horvath's aim in constructing the measure was to operationalize Bordin's (1979) pan-theoretical conceptualization of alliance (Horvath \& Greenberg, 1986, 1989). Horvath engaged in multimethod-multitrait analyses to establish construct validity of the Working Alliance Inventory (Horvath \& Greenberg, 1986). Content validity was assessed by means of an expert panel (Horvath \& Greenberg, 1986). Horvath also found concurrent and predictive validity with the Working Alliance Inventory (Horvath \& Greenberg, 1986, 1989). The literature does not indicate age, gender, 
or race as covariants in working alliance measurement (Kivlighan, 1990; Kivlighan \& Schmitz, 1992; Speight, 1990).

Tracey and Kokotovic (1989) developed a 12-item short-form Working Alliance Inventory from their confirmatory factor analysis study of the Horvath original 36-item measure. On the Working Alliance Inventory-Short, counselors respond using a 7-point scale fully anchored from never (1) to always (7). The possible range of scores is from 12 to 84 with higher scores indicating stronger alliances. Tracey and Kokotovic reported an alpha of .95 for this instrument. Other researchers have employed the Working Alliance Inventory-Short in their work (Kivlighan \& Shaughnessy, 1995; Tryon \& Kane, 1993).

Gough (1960, 1965, 1983, 1987) held that personological specification is best accomplished by means of adjective correlates. Other prominent psychometricians have employed this technology to gain greater clinical knowledge of specific psychological instruments (Dahlstrom, Welsh, \& Dahlstrom, 1972; Gough, 1987; Graham \& McCord, 1985; Hathaway \& Meehl, 1952; Megargee, 1984). Gough's (1960) Adjective Check List was used to obtain the counselors' adjective descriptors of their clients. The Adjective Check List is a standardized list of 300 adjectives (Gough \& Heilbrun, 1983). Jones and Zoppel (1982) clearly described the benefits of using the Adjective Check List in the counselor-as-observer format. They emphasized that the Adjective Check List utilizes no special language and that it is free of 
psychiatric and theoretical terminology which may not have agreed-upon meaning or might act to restrict the range of behavior described. This theoretically free mode of description is ideal for building a personology of a pantheoretical construct such as working alliance. Gough (1983) reported an observer panel's median split-half reliability of .81 for the Adjective Check List when used in the counseloras-observer format.

\section{Procedure}

The contact person at each center distributed a research packet to each recruited subject. Each packet contained a Working Alliance InventoryShort and an Adjective Check List. In addition to these items, each packet included a covering letter, a procedures outline, an informed consent statement, a consent reply card, and a demographic information sheet. In the outline of procedures, the counselors were asked to complete the scales immediately following the next session they had with one client that they had seen at least three times.

Approximately three weeks after the questionnaire packets were mailed a follow-up postcard was sent to all counselors. The mean number of sessions between the commencement of counseling and completion of the research packet was $15(S D=23)$. Consistent with other working alliance studies, there was no significant relationship between the number of sessions and the score on the Working Alliance Inventory-Short. 


\section{Analysis}

Borg and Gall (1989) suggested that a pointbiserial coefficient be used when one variable is continuous (Working Alliance Inventory-Short) and the other is in the form of a genuine dichotomy (each item of the Adjective Check List). Endorsed adjectives were coded 1 and adjectives left blank were coded 0. An alpha level of .01 was set for all analyses. In addition, a standard of two times the number of adjectives expected by chance was adopted to conclude that the significant adjectives produced rap the construct being studied (Forrester, 1984). To manage large numbers of significant correlates, only the 10 strongest positive and negative correlates were considered.

\section{Results}

In this study, one would expect to find three significant adjective correlates by chance. However, point-biserial correlational analysis produced 54 significant adjectives, 18 times what one would expect by chance. Table 1 contains an alphabetized listing of the 10 strongest correlates in each direction. The positive adjective correlates are related to strong working alliances and the negative correlates are related to weak working alliances. Given a number this large and the standards established in the professional literature, a strong claim can be made that these correlates do tap the underlying variance of the construct of working alliance. 
The mean for scores on the Working Alliance Inventory-Short was 67 ( $S D=7 ; 95 \%$ confidence interval $=65.9,68.63)$. The negative skew of scores was similar to other results found in the literature (Cummings, Martin, Hallberg, \& Slemon, 1992; Horvath \& Greenberg, 1986; Horvath \& Marx, 1990; Kiesler \& Watkins, 1989; Kivlighan, Angelone, \& Swafford, 1991; Kivlighan \& Schmitz, 1992; Mallinckrodt \& Nelson, 1991). This skew held for counseling dropouts (Kokotovic \& Tracey, 1990).

\section{Discussion}

The present study examined counselors' adjective descriptors of their clients in relation to working alliance. The results specified the personological dispositions of clients in reference to scores on the Working Alliance Inventory-Short. As Gough (1965) noted, completion of such a personological specification opens a psychological measure to full clinical application. Given the predictive power of the working alliance construct, the descriptors of clients produced by the present study give counselors valuable road signs that can help them navigate the often treacherous journey toward positive therapeutic outcomes.

Knowledge of the adjective descriptors related to strong and weak working affiances can enhance counselors' strategic management of the therapeutic process. For example, the adjective descriptors related to weak alliances contain important process signals for 
counselors. When counselors perceive clients in terms congruent with weak-alliance adjective descriptors, the proper therapeutic task involves building the basic boundaries of the counseling process. Given the extreme immaturity and hostility present in these clients, strenuous structuring of the counseling process may be required. Kernberg, Selzer, Koenigsberg, Carr, and Appelbaum (1989) provided a detailed manual on how counselors can conduct such a structuring. It is only after such structuring that an adequate affiance can be formed and a profitable shift to the presenting problems can take place.

The adjective descriptors related to strong affiances also contain important process signals for counselors. For instance, when a counselor perceives a client in terms congruent with strong-alliance adjective descriptors, the proper counseling tasks for that moment become clear. Clients that present a personological profile related to the strong-alliance adjective descriptors possess both the ego strength and interpersonal skills necessary to form adequate alliances. Thus, counselors encountering such clients can implement interventions appropriate to the presenting problems without hesitation.

The personological specification conducted as part of the present study contains information that can help counselors better manage therapeutic processes. However, some limitations to the present study may restrict the generalizability of the results to other client populations. First, this study examined counselors' experiences of college-aged clients. Thus, 
the application of the findings of this study to other ages should only be made with caution. Second, it must be noted that correlational research cannot answer questions of causality. Therefore, the exact contribution of personality to the formation of working affiance remains an open question.

The purpose of the present study was to fill a gap in the evaluation of measures of working affiance. This gap involved the personological specification of the clients' comportment in counseling from the counselors' perspective. This specification fills out the clinical phenomenology of this measurement. Such a phenomenology can be used to enhance clinical practice.

\section{References}

Bordin, E. S. (1979) The generalizability of the psychoanalytic concept of the working alliance. Psychotherapy: Theory, Research, and Practice, 16, 252-260.

Borg, W. R., \& Gall, M. D. (1989) Educational research. New York: Longman.

Cummings, A. L., Martin, J., Hallberg, E., \& Slemon, A. (1992) Memory for therapeutic events, session effectiveness, and working alliance in short-term counseling. Journal of Counseling Psychology, 39, 306-312. 
Dahlstrom, W. G., Welsh, G. S., \& Dahlstrom, L. E. (1972) An MMPI handbook. Minneapolis, MN: University of Minnesota Press.

Forrester, M. E. (1984) Adjective correlates of the California Personality Inventory scales for normal college students (Doctoral dissertation, Kent State University, 1983). Dissertation Abstracts International, 44, 2892).

Gelso, C. J. , \& Carter, J. A. (1994) Components of the psychotherapy relationship: their interaction and unfolding during treatment. Journal of Counseling Psychology, 41, 296-306.

Gough, H. G. (1960) The Adjective Checklist as a personality assessment research technique. Psychological Reports, 6(Monogr. Suppl. 2), 107122.

Gough, H. G. (1965) Conceptual analysis of psychological test scores and other diagnostic variables. Journal of Abnormal Psychology, 70, 294-302.

Gough, H. G. (1983) Personality correlates of time required to complete work for the Ph.D. degree in psychology. In Spielberger, C. D. \& Butcher, J. N. (Eds.), Advances in personality assessment (pp. 105-127). Hillsdale, NJ: Erlbaum.

Gough, H. G. (1987) CPI administrator's guide. Palo Alto, CA: Consulting Psychologists Press. 
Gough, H. G. , \& Heilbrun, A. B. (1983) The Adjective Check List manual. Palo Alto, CA: Consulting Psychologists Press.

Graham, J. R. , \& McCord, G. (1985) Interpretation of moderately elevated MMPI scores for normal subjects. Journal of Personality, 49, 477-484.

Hathaway, S. R. , \& Meehl, P. E. (1952) Adjective Check List correlates of MMPI scores. (Unpublished manuscript, University of Minnesota, Minneapolis, Department of Psychology)

Horvath, A. O. (1994a) Empirical validation of Bordin's pantheoretical model of the alliance: the Working Alliance Inventory perspective. In Horvath, A. O. \& Greenberg, L. S. (Eds.), The working alliance (pp. 109-128). New York: Wiley.

Horvath, A. O. (1994b) Research on the alliance. In Horvath, A. O. \& Greenberg, L. S. (Eds.), The working alliance (pp. 259-286.) New York: Wiley.

Horvath, A. O., \& Greenberg, L. (1986) The development of the working alliance inventory. In Greenberg, L. S. \& Pinsof, W. M. (Eds.), The psychotherapeutic research process: a research handbook (pp. 529556). New York: Guilford.

Horvath, A. O., \& Greenberg, L. S. (1989) Development and validation of the Working Alliance Inventory. Journal of Counseling Psychology, 36, 223-233. 
Horvath, A. O., \& Marx, R. O. (1990) The development and decay of the working alliance during timelimited counselling. Canadian Journal of Counselling, 24, 240-259.

Horvath, A. O., \& Symonds, B. D. (1991) Relation between working alliance and outcome in psychotherapy: a meta-analysis. Journal of Counseling Psychology, 38, 139-149.

Jones, E. E., \& Zoppel, C. L. (1982) Impact of client and therapist gender on psychotherapy process and outcome. Journal of Consulting and Clinical Psychology, 50, 259-272.

Kernberg, O. F., Selzer, M. A., Koenigsberg, H. W., Carr, S. C., \& Apfelbaum, A. H. (1989) Psychodynamic psychotherapy of borderline patients. New York: Basic Books.

Kiesler, D. J., \& Watkins, L. M. (1989) Interpersonal complementarity and the therapeutic alliance: a study of relationship in psychotherapy. Psychotherapy, 26, 183-193.

Kivlighan, D. M. (1990) Relation between counselors' use of intentions and clients' perception of working alliance. Journal of Counseling Psychology, 37, 2732 .

Kivlighan, D. M., Angelone, E. O., \& Swafford, K. G. (1991) Live supervision in individual supervision: effects on therapist's intention use and client's 
evaluation of session effect and working alliance.

Professional Psychology: Research and Practice, 22, 489-495.

Kivlighan, D. M., \& Schmitz, P. J. (1992) Counselor technical activity in cases with improving working alliances and continuing-poor working alliances. Journal of Counseling Psychology, 39, 32-38.

Kivlighan, D. M. , \& Shaughnessy, P. (1995) Analysis of the development of the working alliance using hierarchical linear modeling. Journal of Counseling Psychology, 42, 338-349.

Kokotovic, A. M. , \& Tracey, T. J. (1990) Working alliance in the early phase of counseling. Journal of Counseling Psychology, 37, 16-21.

Luborsky, L. (1994) Therapeutic alliances as predictors of psychotherapy outcomes: factors explaining predictive success. In Horvath, A. O. \& Greenberg, L. S. (Eds.), The working alliance (pp. 38-50). New York: Wiley.

Mallinckrodt, B. , \& Nelson, M. L. (1991) Counselor training level and the formation of the psychotherapeutic working alliance. Journal of Counseling Psychology, 38, 133-138.

Marziali, E., \& Alexander, L. (1991) The power of the therapeutic relationship. American Journal of Orthopsychiatry, 61, 383-391. 
Megargee, E. I. (1972) The California Psychological Inventory handbook. San Francisco, CA: JosseyBass.

Megargee, E. I. (1984) A new classification system for criminal offenders: differences among the types on the Adjective Checklist. Criminal Justice and Behavior, 11, 349-376.

Safran, J. D., \& Wallner, L. K. (1991) The relative predictive validity of two therapeutic alliance measures in cognitive therapy. Psychological Assessment: A Journal of Consulting and Clinical Psychology, 3, 188-195.

Sexton, T. L. , \& Whiston, S. C. (1994) The status of the counseling relationship: an empirical review, theoretical implications, and research directions. Counseling Psychologist, 22, 6-78.

Speight, S. L. (1990) The working alliance and therapeutic outcome in cross-cultural counseling: a preliminary investigation (Doctoral dissertation, Ohio State University, 1990). Dissertation Abstracts International, 51, 2075.

Tichenor, V., \& Hill, C. E. (1989) A comparison of six measures of working alliance. Psychotherapy, 26, 195-199.

Tracey, T. J., \& Kokotovic, A. M. (1989) Factor structure of the Working Alliance Inventory. Psychological Assessment: A Journal of Consulting and Clinical 
Psychology, 3, 207-210.

Tryon, G. S., \& Kane, A. S. (1993) Relationship of working alliance to mutual and unilateral termination.

Journal of Counseling Psychology, 40, 33-36. 
Table 1

Alphabetical Listing of 10 Strongest Adjective Correlates In Both Directions $(n=85)$

\begin{tabular}{lll}
\hline \multicolumn{1}{c}{ Direction } & \multicolumn{1}{c}{ Adjective } & $r_{\mathrm{p}-\mathrm{b}}$ \\
\hline Positive & Affectionate & 0.37 \\
& Considerate & 0.32 \\
& Cooperative & 0.37 \\
& Friendly & 0.37 \\
& Good-natured & 0.40 \\
& Honest & 0.37 \\
Insightful & 0.32 \\
Responsible & 0.35 \\
Negative & Sincere & 0.31 \\
& Strong & 0.36 \\
& Argumentative & 0.43 \\
& Arrogant & 0.43 \\
& Boastful & 0.38 \\
& Cynical & 0.45 \\
& Defensive & 0.45 \\
& Distrustful & 0.42 \\
Evasive & 0.47 \\
Infantile & 0.51 \\
Sulky & 0.45 \\
Unstable & 0.38 \\
\hline
\end{tabular}

Note. All $r_{\mathrm{p} b \mathrm{~b}}$ significant at $p<.01$. 